\title{
Análisis crítico del modelo pedagógico de las universidades venezolanas
}

Romero, Néstor L.*

\section{Resumen}

La Constitución de la República Bolivariana de Venezuela de 1.999 establece, entre otras cosas, una nueva concepción y misión de la educación, que exige, a la gerencia de cada Universidad, hacer las transformaciones que se requieran para su actualización y el cumplimiento de su nueva misión. El objetivo de este trabajo es hacer un análisis descriptivo, explicativo y crítico del modelo pedagógico contenido en la Ley de Universidades, tomando en cuenta los aportes de las recientes teorías del conocimiento, la educación, la pedagogía, la gerencia y la nueva concepción y misión de la educación. Aplicando el método analítico-sintético se obtuvo como resultado: 1) Que la división del conocimiento en disciplinas, está desactualizado y ha generado frondosidad curricular y administrativa, aislacionismo entre las facultades y grupos que ejercen poder y en oportunidades se resisten a cambiar 2) Que existe la necesidad de asumir y aplicar al modelo universitario, los cambios respecto a la concepción compleja del conocimiento y de la pedagogía y la nueva concepción de la educación establecida en la Constitución Nacional.

Palabras clave: Modelo pedagógico universitario, concepción educativa, concepción pedagógica, transformación universitaria, Ley de Universidades.

Recibido: 20-05-09. Aceptado: 30-04-10

Economista, profesor titular de la Universidad del Zulia, Investigador del Centro Experimental de Estudios Latinoamericanos (CEELA) y cursante del doctorado en Ciencias Sociales, Mención Gerencia de dicha Universidad. nromerom@cantv.net. 


\title{
A Critical Analysis of the Pedagogical Model of Venezuelan Universities
}

\begin{abstract}
The Constitution of the Bolivarian Republic of Venezuela, enacted in 1999, dictates, among other things, a new concept and mission for education, which demands that the management at each university make the transformations required to bring the university up to date and fulfill its new mission. The objective of this study is to make a descriptive, explanatory and critical analysis of the pedagogical model contained in the Law of Universities, considering contributions of recent theories regarding knowledge, education, pedagogy, management and the new concept and mission of education. By applying the analytic-synthetic method, it was detected that: (1) the division of knowledge into disciplines is out of date and has generated curricular and administrative excesses, isolationism among the different faculties and groups that exercise power and, occasionally, resistance to proposed changes; and (2) there is a need to adopt and apply to the university model the changes regarding the complex concept of knowledge and pedagogy and the new concept of education set forth in the National Constitution.
\end{abstract}

Key words: University pedagogical model, educational concept, pedagogical concept, university transformation, Law of Universities.

\section{Introducción}

La vigente Ley de Universidades de Venezuela contiene la concepción del conocimiento, del hombre, de la educación y de la pedagogía, que en el momento de su elaboración, predominó entre los miembros del Congreso Nacional que la aprobaron el 08 de Septiembre de 1970. Hoy a la luz de los más recientes aportes de las teorías del conocimiento, de la educación, de la pedagogía y demás ciencias humanas y sociales, las Universidades deben autoevaluarse y autotransformarse para que continúen cumpliendo la misión que en la actualidad se espera de ellas con la mayor eficacia, eficiencia, calidad y pertinencia social que les sea posible.

En este sentido en Venezuela algunos académicos tanto del sector público como del privado, en las últimas dos dé- cadas, han venido intentando transformar a las Universidades en simples proveedoras de la mano de obra que el mercado necesita y evaluarlas sólo con criterios economicistas de eficiencia, productividad, relación beneficio-costo, propios del sistema capitalista neoliberal.

A partir de 1999 la Constitución de la República Bolivariana de Venezuela, establece, entre otras cosas, que la Educación, además de un derecho y un deber, constituye un instrumento de desarrollo personal y colectivo (Asamblea Nacional Constituyente de la República Bolivariana de Venezuela, 1999).

Aún cuando se trata de dos concepciones de educación diferentes y se han hecho intentos de transformarlas para que en ambos momentos cumplieran la misión que les corresponde de acuerdo a cada una de esas concepciones, hasta ahora los resultados de esos 
intentos no han sido muy satisfactorios, ya que continúan funcionando con los mismos modelos teóricos que en el momento de su aprobación fueron considerados actualizados y apropiados para el progreso de nuestro país, como se dice en dicha Ley, pero que ahora esos modelos en su mayoría han sido superados.

Aunque la transformación debe ser integral, y abarcar todas las funciones y servicios que prestan las Universidades, en este trabajo se analizará de manera crítica, el modelo pedagógico contenido en la vigente Ley de Universidades, así como su gerencia, por considerar que son los elementos más importante para producir los cambios que posibiliten la permanente elevación de los niveles de eficacia, eficiencia, calidad y pertinencia social de los servicios que prestan esas Instituciones.

Tomando en cuenta las tendencias teóricas actuales, en esas áreas del conocimiento, y los resultados del análisis descriptivo, explicativo y crítico, del modelo Pedagógico y gerencial contenido en la Ley de Universidades, se detectaron algunas debilidades y la necesidad de que la gerencia de cada Universidad asuma y aplique los cambios que requiera según sus características particulares.

\section{Algunas precisiones necesarias sobre educación, conocimiento, pedagogía y gerencia}

Sin pretender crear nuevos conceptos, sino con el fin de dejar establecida la posición y el uso que se le está dando a los términos que se utilizan, se van a explicar brevemente.
La Universidad en Venezuela mantiene en vigencia las tres funciones fundamentales que le asigna la respectiva Ley: Docencia (educación), Investigación y Extensión. Esas tres funciones implican: la asimilación, creación, revisión, acumulación, difusión y aplicación del conocimiento para solucionar problemas de la región y el país.

En cada una de esas funciones, para mejorar las posibilidades de obtener un cumplimiento cada vez más eficaz, eficiente, de buena calidad y pertinente, es muy importante conocer, asumir una posición al respecto, y aplicar, los más recientes avances de las teorías de la educación, del conocimiento, de la pedagogía y de la gerencia.

\subsection{Educación}

"Etimológicamente, la educación tiene dos significados: educare que significa conducir, llevar a un hombre de un estado a otro; y educere que significa extraer, sacar algo de dentro del hombre" (Vicaría Episcopal de Educación del Arzobispado de Buenos Aires, 2008).

La educación implica, entonces, un proceso para cambiar el hombre conducido por los hombres (los que conforman el sistema educativo) y una actitud del hombre (el que esté dispuesto a cambiar para mejorar) para desarrollar sus propias facultades. Es más apropiado, entonces, considerarla un proceso de enseñanzaaprendizaje.

La enseñanza es el proceso mediante el cual se comunican y/o trasmiten conocimientos y/o información. Es más restringido que el concepto de educación, ya que ésta tiene por objeto la formación 
integral del hombre, que además del conocimiento debe incluir el desarrollo de facultades, actitudes, valores éticos, estéticos, destrezas, habilidades, motivación, deseos de superación.

El aprendizaje es el otro significado de la educación, en el que la persona que está dispuesta a desarrollar sus potencialidades, constituye el objeto de estudio, tomando en cuenta sus características, sus experiencias, sus motivaciones, sus destrezas, habilidades, el contexto espacial, temporal y cultural, para aumentar las posibilidades de que el proceso dé los resultados previamente definidos.

El concepto de educación es más amplio que el de enseñanza-aprendizaje $y$ tiene fundamentalmente un sentido espiritual y moral, siendo su objeto de estudio la formación integral de la persona humana. En la medida en que esa persona domine, autocontrole y autodirija sus potencialidades: deseos, tendencias, juicios, raciocinio y voluntad, podrá contribuir de una manera más eficaz y eficiente a su propio desarrollo y a la construcción de una sociedad en permanente superación. "La educación es el conjunto de conocimientos, órdenes y métodos por medio de los cuales se ayuda al individuo en el desarrollo y mejora de sus facultades intelectuales, morales y físicas. La educación no crea facultades en el educando, sino que coopera en su desenvolvimiento y precisión" (Navarro, 2008).

Es necesario considerar también que además de la educación formal o sistematizada, existe la informal o no sistematizada que ejerce la sociedad en general y los medios de comunicación social de manera particular. Entre estos dos sistemas de educación es muy frecuente en- contrar contradicciones, especialmente cuando se trata de motivar y educar en principios éticos, valores y actitudes, ya que el sistema formal debe responder al interés de la nación y en cambio el informal que difunden los medios privados de comunicación, generalmente responde a intereses particulares y/o de grupos.

La educación formal debe tomar muy en cuenta la existencia de estos intereses contrapuestos, para diseñar planes, estrategias y actividades concebidos desde el enfoque de la complejidad, para contrarrestarlos y/o transformarlos en complementarios.

\subsection{Conocimiento}

El conocimiento, en sentido amplio, constituye el principal e indispensable elemento que posibilita la realización de casi todas las actividades humanas. Salvo las actividades instintivas, las demás requieren de un proceso previo de enseñanza-aprendizaje. Es la base del proceso civilizatorio de la humanidad.

De allí que la asimilación, difusión, creación, desarrollo, acumulación y aplicación del conocimiento, sea quizás la más importante tarea individual y colectiva de toda sociedad para poder desarrollarse.

En Venezuela esa misión le corresponde a todo el sistema educativo en general y a las Universidades de manera particular y específica, por mandato de las respectivas Leyes. Estas instituciones para aumentar las posibilidades del cumplimiento exitoso de esa misión, deben estar permanentemente planteándose, entre otros, los siguientes interrogantes: ¿qué es el conocimiento?, ¿qué es la 
ciencia?, ¿cuál es el papel de la ciencia?, ¿qué es la realidad?, ¿qué es el hombre?, ¿qué es el desarrollo?

La respuesta a este interrogante implica analizar y definir el conocimiento científico, la ciencia, la realidad, la sociedad, la nación, el Estado, el poder, el hombre, el desarrollo, así como también sus interrelaciones y la escala de valores que determina el uso que se le debe dar a la ciencia y a la educación.

Hoy la tendencia predominante es a considerar que la realidad es un sistema en permanente interacción y cambio. A nivel ontológico se admite el azar. Por ello éste puede conjugarse o complementarse con el orden. El progreso y la entropía se encuentran y son simultáneos. A pesar de las crisis, las contradicciones o el caos, el hombre puede generar estructuras superiores a las actuales, no siempre el caos genera más caos (Méndez, 2003).

La complejidad e interrelación de los elementos que conforman la realidad sustituye la relación causa-efecto y exige abordar los problemas con una visión transdisciplinar, sin la parcelación impuesta por la disciplinaridad. La creatividad constituye el elemento dinámico en la producción del conocimiento.

En cuanto a los aspectos gnoseológicos del conocimiento, su naturaleza, se concibe ahora como resultado de la interacción, del diálogo del hombre que vive en la naturaleza, con sus semejantes y con sus circunstancias.

Respecto a los fundamentos axiológicos, la tendencia es a rescatar los valores relacionados con la vida, el ambiente, la libertad, la responsabilidad social, etc., con el fin de contrarrestar el neolibe- ralismo económico, el individualismo, el socialismo, el Estatismo, la maximización de la ganancia, el crecimiento económi$\mathrm{co}$, como valores superiores.

Sobre estas nuevas concepciones, Morin (1997) plantea la necesidad de superar las alternativas clásicas: unidad/diversidad, azar/necesidad, cantidad/cualidad, sujeto/objeto, y el rechazo al accidente, al evento, a lo aleatorio, a lo individual, que se convirtió en un reduccionismo que deforma la realidad y limita las posibilidades de continuar el desarrollo del conocimiento y la solución de problemas.

El nuevo enfoque que Morin propone, no destruye las alternativas clásicas ni las interrelaciones sino que las amplía, y al efecto dice: "los términos alternativos se vuelven términos antagonistas, contradictorios y, al mismo tiempo, complementarios en el seno de una visión más amplia que deberá reencontrar y afrontar nuevas alternativas" (Morin, 1997: 8182). Define a la complejidad como: "un tejido (complexus: lo que está tejido en conjunto) de constituyentes heterogéneos inseparablemente asociados: presenta la paradoja de lo uno y lo múltiple. Al mirar con más atención, la complejidad es, efectivamente, el tejido de eventos, acciones, interacciones, retroacciones, determinaciones, azares, que constituyen nuestro mundo fenoménico" (Morin, 1997: 32). "El orden y el desorden siendo enemigos uno del otro, cooperan, de alguna manera, para organizar el universo" (Morin, 1997: 92).

Sin pretender agotar el análisis sobre las interrogantes planteadas, cualquier programa de transformación que promueva la gerencia de cada Universidad, debe dejar abierta la posibilidad de 
estar permanentemente incorporando los nuevos avances de la ciencia y de la tecnología.

Para los efectos de este análisis y tratando de incorporar esos nuevos enfoques, se considera al conocimiento científico como un proceso permanente mediante el cual el ser humano, ubicado en determinado contexto, mediante el ejercicio de sus facultades sensoriales e intelectuales: percibe, analiza, proyecta, se forma imágenes y representaciones de sí mismo, de la sociedad y de todas las cosas que conforman el universo y las comunica a otros seres humanos, con el fin de que el diálogo con sus semejantes confirme, niegue o modifique dichas imágenes y representaciones y puedan ser útiles para describir y explicar la realidad y mejorar las condiciones de vida tanto del individuo como de la sociedad. En el Diagrama 1 resumimos este concepto.

La definición propuesta contiene las cuatro relaciones que Eduardo Nicol considera debe contener el conocimiento científico: la relación epistemológica; la relación lógica (metodológica); la ubicación histórica (contextual) y la relación dialógica (Nicol, 1965).

\subsection{La pedagogía}

Rafael Flórez (2005), prefiere la expresión ciencias de la educación que además la considera todavía en construcción. Sin embargo describe e interrelaciona el proceso de conocer, con esa ciencia, de una manera que puede ser útil a los fines de establecer el objeto de estudio y se tome en cuenta para el diseño de un modelo pedagógico.

Distingue tres momentos en lo que él llama la dinámica productiva del conocimiento:

En un primer momento, los individuos obtienen el conocimiento perceptivo a través de los sentidos. Se le denomina conocimiento vulgar, de sentido común, no plenamente consciente, no reflexivo. Considera que no es suficiente el reconocimiento de la existencia del mundo de los objetos físicos, que él denomina Mundo 1.

En un segundo momento, a los individuos le surgen dudas, interrogantes respecto al conocimiento vulgar previamente adquirido y, estos interrogantes le generan cambios de actitud, y le estimulan la búsqueda de respuestas, la refle-

\section{Diagrama 1 \\ Elementos Constitutivos de la Concepción de Complejidad}

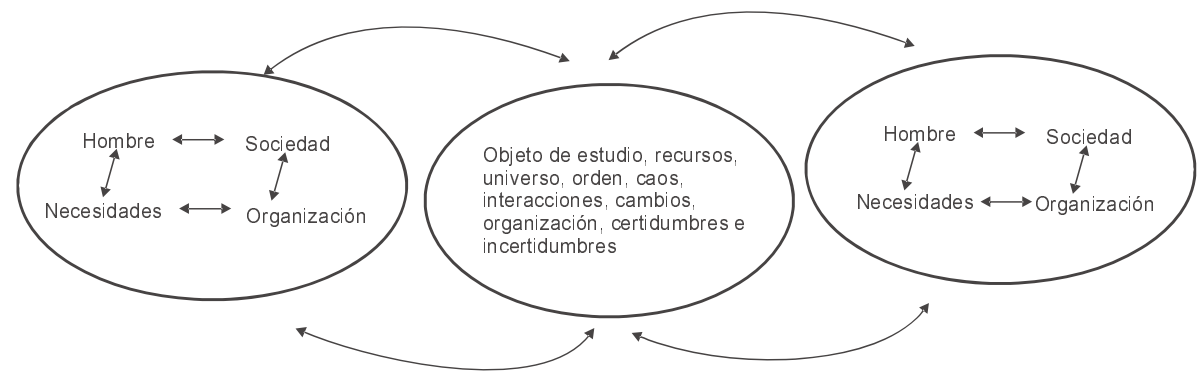

Fuente: elaboración propia. 
xión y análisis crítico del conocimiento que hasta ese primer momento había adquirido. Este segundo momento lo denomina Mundo 2.

Luego en un tercer momento los individuos se proponen conocer mejor el objeto de estudio: definiéndolo mejor, identificando sus elementos constitutivos, sus características, sus interrelaciones positivas y negativas entre sus propios elementos y con el entorno y a encontrar las correspondientes explicaciones.

Es el momento de la actividad autoconsciente y reflexiva que produce una cierta respuesta al problema o dudas que se habían planteado. Para la producción de la respuesta emiten juicios, se comprometen con un nombre y se esfuerzan por liberarse y superar los condicionantes empíricos y psico-socio-culturales que le permitan asumir la actitud de un espectador imparcial con mayores posibilidades de generar nuevos conocimientos. Este momento lo denomina Mundo 3.

Así se producen las hipótesis que llamamos científicas, conceptos, descripciones y argumentos que permiten entender mejor los estados del Mundo $1 \mathrm{y}$ del Mundo 2. Semejante reconocimiento de la existencia autónoma y objetiva del Mundo 3, como producto de la actividad intelectual humana, implica una triple consecuencia epistemológica:

En primer lugar, contra el realismo tradicional e ingenuo que consideraba el conocimiento como una copia del objeto real, opta por el constructivismo iniciado por Kant, para quien todo conocimiento era una construcción del sujeto, a partir de la síntesis de la estructura categorial del entendimiento con la experiencia sensible.

En segundo lugar, tal constructivismo no se detiene ni se agota en el sujeto, pues los productos que va segregando se salen de las manos, se le independizan de cierta manera, configurando un mundo científico-cultural que Popper llama Mundo 3.

En tercer lugar, si el Mundo 3 como mundo objetivo se opone a la actividad subjetiva es para volver a depender de ella, pues es sólo la actividad humana que denominamos enseñanza la que permite que los individuos se apropien subjetivamente del mundo de las ciencias, lo piensen y le asignen nuevos significados que enriquecerán al Mundo 3 y a sus nuevos generadores. Tal proceso debe constituirse en la positividad objeto de estudio de la pedagogía (Flórez, 2005).

A pesar de que el autor que se comenta parece que considera sólo el Mundo 3 como el objeto de estudio de la pedagogía, dejando fuera a los primeros momentos en el proceso de conocer que se corresponderían con los niveles de educación preescolar y primaria, se considera útil para la educación superior esa descripción del proceso de conocer para diseñar planes, estrategias y actividades que hagan más eficaz, eficiente, de mejor calidad y pertinencia social los servicios que prestan la Universidades venezolanas.

Respecto a la finalidad de la pedagogía, a su razón de ser, el mencionado autor considera que es La formación de hombres, como un proceso de humanización de los niños hasta propiciarles la mayoría de edad, y con ella niveles supe- 
riores de autonomía y de racionalidad, como proponía Kant.

Ese concepto de formación humana, que aún cuando tenga todos los condicionantes del exterior, se produce desde el interior de los individuos, implica la aceptación del enfoque constructivista, y como ya hemos expuesto, consideramos que al momento de diseñar planes y estrategias para el proceso de enseñanza aprendizaje hay que tomar en cuenta los diferentes aporte que han hecho las diferentes teorías pedagógicas y no magnificar la importancia de alguna de ellas.

El concepto de formación humana, que actualmente se considera debe ser asumido por las universidades, implica tomar en cuenta también que el cerebro humano tiene, entre otras, tres funciones fundamentales: instintivas, emotivas y racionales; y las emotivas constituyen el motor que impulsa las racionales. Los estímulos, las motivaciones, siguen siendo muy importantes para lograr que los alumnos aprendan, no sólo conocimientos sino también: a ser, a hacer, a investigar, a descubrir, a aprender, etc.

En este sentido es oportuno señalar que aunque hoy en nuestro país se le está dando vigencia al constructivismo, no se debe olvidar que sin los materiales y herramientas adecuadas, es muy difícil construir algo. Utilizando la comparación del cerebro humano con las computadoras, si a éstas no le proporcionamos previamente un sistema operativo e información, no podrá realizar los cómputos que se esperan de ellas. Se debe entonces utilizar los aportes de las diferentes teorías pedagógicas, que según sean los objetivos del proceso de enseñanza-aprendizaje, sean aplicables al momento de di- señar el respectivo modelo pedagógico universitario.

Aunque las diferentes teorías pedagógicas, a lo largo de su historia, han señalado diferentes elementos y diferentes énfasis en sus relaciones, explicaciones y respuestas, existe consenso en que hay que responder, por lo menos, a los siguientes interrogantes fundamentales:

- ¿Qué tipo de hombre se debe formar?

- ¿Cómo o con cuáles estrategias, metodologías y técnicas?

- ¿A través de qué contenidos, entrenamientos o experiencias?

- ¿A qué ritmo debe adelantarse el proceso de formación?

- ¿Quién predomina o dirige el proceso: el maestro o el alumno?

Edgar Morin en su libro "Los siete saberes necesarios a la educación del futuro", aunque no se refiere específicamente a la pedagogía, sino a la educación en general, también hace énfasis en la necesidad de formar un nuevo ser humano que adquiera consciencia de su condición humana, del proceso de conocer, de la pertinencia del conocimiento, de su identidad terrenal, de las incertidumbres, de la comprensión y de la ética del género humano; y que esa toma de conciencia se traduzca en la voluntad de realizar la ciudadanía terrenal (Morin, 2000).

Respecto a la conducta del hombre y la manera en que se forma, es oportuno citar una de las frases de Platón que aparece en el buscador www.google bajo "Frases de Platón": "El cuerpo humano es el carruaje; el YO, el hombre que lo conduce; el pensamiento son las riendas, y los sentimientos los caballos". 


\subsection{La gerencia}

En este trabajo utilizaremos el término Gerencia en sentido amplio, compartiendo así la concepción de Drucker (1992), según la cual, el gerente no es un jefe, un manager, porque no necesariamente tiene que tener personal bajo su coordinación y supervisión, sino que tiene como función planificar, dirigir, controlar y evaluar el desempeño y el logro de los objetivos y metas de una empresa privada o pública. Son entonces las funciones y su importancia dentro de las organizaciones, los elementos utilizados para definir a la gerencia como término más apropiado que el de administración o el de teoría de la Organización (TO) utilizado por Ibarra en su análisis sobre la educación superior (Ibarra (1996).

Si embargo hay que aclarar que cada organización humana tiene objetivos y características propias que le dan su especificidad organizacional y factores contextuales que inciden en su estructura (Ibarra 1996), pero también hay principios de la economía y teorías gerenciales que son lo suficientemente generales que pueden ser aplicables no sólo a las empresas privadas, sino también a toda organización humana.

Lógicamente el desempeño y el logro de objetivos y metas, implica la aplicación del Principio Económico Fundamental que sirve para entender el funcionamiento del proceso productivo. Según este principio en todo proceso productivo se plantea el problema de que existen múltiples necesidades ilimitadas y recursos limitados que tienen usos alternativos, por lo que resulta indispensable hacer un uso, lo mas racional posible, de esos limitados recursos para poder obtener la mayor satisfacción posible de las diversas necesidades.

Consideramos necesario hacer esta precisión porque sobre este principio se han hecho exageradas aplicaciones y se ha generado la falsa creencia de que no se debe aplicar en el sector público. Aún cuando los fines del Estado y de sus Instituciones fundamentales no son obtener el máximo beneficio monetario al menor costo, la racionalidad del mencionado principio exige evitar o minimizar el desperdicio, la contaminación, la ociosidad, las deficiencias y al mismo tiempo producir el mejor servicio en términos de eficacia, calidad, eficiencia, rapidez, población servida, etc.

El argumento de que la eficiencia, la maximización del beneficio y la reducción de los costos genera desempleo de la mano de obra, puede ser manejado dándole el uso alternativo que caracteriza a los recursos, es decir reubicando al personal que esté subutilizado, en otras actividades en las cuales pueda generar beneficios adicionales a la población a ser servida. Taylor (1983) demuestra que la aplicación del principio de la racionalidad económica no es perjudicial al trabajador y por el contrario es necesario para el progreso de toda la economía y la generación de puestos de trabajo.

En las universidades el objeto de trabajo es el conocimiento y los miembros de su respectiva comunidad (profesores y estudiantes); $y$ en las complejas organizaciones sociales de la actualidad, el conocimiento es quizás el elemento más importante para alcanzar el éxito en la búsqueda de soluciones a los problemas relacionados con el desarrollo de la nación. 
Es indispensable entonces que cualquier programa de reforma tenga en cuenta, entre otras cosas, los seis (6) factores que Drucker (1999) señala como determinantes de la productividad de los que trabajan con el conocimiento: 1. Definición precisa de la tarea. Concepción del conocimiento, de la ciencia, sus métodos, etc., del programa y del proyecto específico, etc. 2. La autodirección o autonomía del trabajador. 3. La innovación permanente. 4. El aprendizaje y enseñanza permanente. 5. En el control de la productividad debe dársele igual importancia a la calidad que a la cantidad. 6 . El trabajador intelectual debe ser tratado como un activo de la empresa y no como un gasto. Recibir las mejores remuneraciones y beneficios sociales y debe desear trabajar para la institución por encima de otras. Es decir, estar identificado con ella.

\section{El modelo universitario}

Para poder establecer si la ley de Universidades vigente contiene un modelo teórico se debe partir de lo que se entiende por modelo: representación teórica de un conjunto coherente de elementos interrelacionados que conforman un todo con un fin determinado. Se relaciona con el entorno recibiendo recursos, insumos, información y energía; y mediante un proceso interno de producción los transforma en bienes y/o servicios que entrega al entorno.

De acuerdo a los principios de planificación sistemática, estratégica y participativa, se analiza el modelo universitario venezolano en base a sus principales elementos constitutivos, a saber: definición, valores, visión, misión, objetivos, re- cursos, actividades, organización, control, evaluación y ajustes.

Aunque el objeto de estudio de este trabajo es el análisis crítico el modelo pedagógico de las Universidades venezolanas se debe analizar el modelo completo contenido en la vigente ley de Universidades, porque partimos de que el mundo es complejo y está constituido por una multiplicidad de elementos interrelacionados en diferentes direcciones que no deben ser analizados en forma aislada.

En el Cuadro 1 se presenta un resumen de los elementos que definen el modelo universitario y que están todos contenidos y relacionados en la vigente ley de Universidades de Venezuela.

En la mencionada ley se define a la universidad como "una comunidad de intereses espirituales que reúne a profesores y estudiantes en la tarea de buscar la verdad y afianzar los valores trascendentales del hombre" (Congreso de la República de Venezuela. Ley de Universidades 1970. art. 1).

Esa definición parte del supuesto de que profesores y estudiantes forman una comunidad de intereses espirituales que, aunque cada uno de los individuos que conforman esa comunidad tenga otros intereses diferentes, todos tienen una tarea, un fin común: buscar la verdad y afianzar los valores trascendentales del hombre.

Sin embargo, ante la posibilidad de que no se haya logrado en las universidades venezolanas la unificación de toda la comunidad universitaria en la misión de buscar la verdad, se plantea la necesidad de realizar una investigación que permita determinar el nivel de identificación existente. 


\section{Cuadro 1 \\ Análisis del modelo universitario contenido en la vigente Ley de Universidades}

\begin{tabular}{|c|c|c|}
\hline $\begin{array}{c}\text { Elementos } \\
\text { Constitutivos } \\
\text { de un Modelo }\end{array}$ & Concepción Contenida en la Ley & $\begin{array}{l}\text { Títulos, Capítulos } \\
\text { y Artículos que los } \\
\text { contienen }\end{array}$ \\
\hline \multirow{7}{*}{ Definiciones } & ${ }^{*}$ Comunidad de intereses espirituales. & Título I art. 1 y 2 \\
\hline & ${ }^{*}$ Miembros de la comunidad: profesores y Estudiantes. & \\
\hline & *Instituciones al servicio de la nación & \\
\hline & $\begin{array}{l}{ }^{*} \text { Concepción del conocimiento: Producto dividido en } \\
\text { disciplinas o ramas del saber que se integran en la unidad } \\
\text { de la Universidad. }\end{array}$ & Artículos 47 y 132 \\
\hline & $\begin{array}{l}\text { *Concepción de la educación: Como formación integral y } \\
\text { capacitación. }\end{array}$ & $\begin{array}{l}\text { Titulo I, art.3, } \\
\text { Título III Cap. II }\end{array}$ \\
\hline & $\begin{array}{l}{ }^{*} \text { Concepción pedagógica: Predominio del docente que } \\
\text { enseña y el alumno que memoriza el saber recibido. }\end{array}$ & Art. $145-150$ \\
\hline & *Concepción del hombre: Materia y Espíritu. & Título | art. 1 \\
\hline \multirow{7}{*}{ Valores } & *La verdad & Título | art. 1 \\
\hline & *Los valores transcendentales del hombre & Título | art. 1 \\
\hline & *La Libertad & Título I art. 4 y 9 \\
\hline & *La democracia & $\begin{array}{l}\text { Título I art. } 30-35 \text { y } \\
\text { Título III art. } \\
167-172\end{array}$ \\
\hline & ${ }^{*}$ La Justicia Social & Título I art. 4 y 9 \\
\hline & *La Solidaridad Humana & Título I art. 4 \\
\hline & ${ }^{*}$ El progreso y el desarrollo de la nación. & Título I art. 3 \\
\hline \multirow[t]{2}{*}{ Visión } & $\begin{array}{l}\text { Ser Instituciones al servicio de la nación y a ellas } \\
\text { corresponde colaborar en la orientación de la vida del país } \\
\text { mediante su contribución doctrinaria en el esclarecimiento } \\
\text { de los problemas nacionales. }\end{array}$ & Título I art. 2 \\
\hline & $\begin{array}{l}\text { *Realizar una función rectora en la educación, la cultura y la } \\
\text { ciencia. }\end{array}$ & Título | art. 3 \\
\hline \multirow[t]{2}{*}{ Misión } & $\begin{array}{l}\text { *Crear, asimilar y difundir el saber mediante la Investigación } \\
\text { y la enseñanza. }\end{array}$ & \\
\hline & $\begin{array}{l}{ }^{*} \text { Completar la formación integral iniciada en los ciclos } \\
\text { educacionales anteriores. }\end{array}$ & \\
\hline
\end{tabular}




\section{Cuadro 1 (Continuación)}

\begin{tabular}{|c|c|c|}
\hline $\begin{array}{l}\text { Elementos } \\
\text { Constitutivos } \\
\text { de un Modelo }\end{array}$ & Concepción Contenida en la Ley & $\begin{array}{l}\text { Títulos, Capítulos } \\
\text { y Artículos que los } \\
\text { contienen }\end{array}$ \\
\hline \multirow{4}{*}{ Objetivos } & $\begin{array}{l}{ }^{*} \text { Asimilar, crear, desarrollar, difundir y aplicar el } \\
\text { Conocimiento, la educación y la cultura al servicio del } \\
\text { progreso y el desarrollo de la nación. }\end{array}$ & Título I art. 3 \\
\hline & $\begin{array}{l}{ }^{*} \text { Colaborar en la orientación de la vida del país, mediante su } \\
\text { contribución doctrinaria en el esclarecimiento de los } \\
\text { problemas nacionales. }\end{array}$ & Título I art. 2 \\
\hline & $\begin{array}{l}\text { *Completar la formación integral iniciada en los ciclos } \\
\text { educacionales anteriores. }\end{array}$ & Título I art. 3 \\
\hline & $\begin{array}{l}\text { *Formar los equipos profesionales y técnicos que necesita } \\
\text { la nación para su desarrollo y progreso. }\end{array}$ & Título I art. 3 \\
\hline \multirow{3}{*}{ Actividades } & *Investigación & $\begin{array}{l}\text { Título III art. } \\
132-137\end{array}$ \\
\hline & ${ }^{*}$ Docencia & $\begin{array}{l}\text { Título III Cap. II } \\
\text { Art. } 145-161\end{array}$ \\
\hline & *Extensión (Cultura y Deporte) & $\begin{array}{l}\text { Título III Secciones } \\
15 \text { y } 16 . \text { art. } \\
138-144\end{array}$ \\
\hline \multirow{5}{*}{ Recursos } & ${ }^{*}$ Aportes del Estado asignados en el presupuesto & Título I art. 13 \\
\hline & ${ }^{*}$ Rentas e ingresos propios de las Universidades & $\begin{array}{l}\text { Título III Sección } \\
13, \text { art. } 130-131\end{array}$ \\
\hline & *Aranceles & $\begin{array}{l}\text { Título I art. } 11 \text { y } \\
\text { Título III art. } 26\end{array}$ \\
\hline & *Personal docente y de investigación & $\begin{array}{l}\text { Título III Sección } \\
10 \text { art. } 83-114\end{array}$ \\
\hline & *Personal administrativo y obrero & $\begin{array}{l}\text { Título III art. } 26 \text {, } \\
36,62\end{array}$ \\
\hline \multirow{7}{*}{ Organización } & ${ }^{*}$ Consejo Nacional Universitario & Título II art. 18-23 \\
\hline & ${ }^{*}$ Claustro Universitario & Título III art. 30 \\
\hline & ${ }^{*}$ Consejo Universitario & Título III art. 24-27 \\
\hline & ${ }^{*}$ Autoridades Rectorales & Título III art. 28-42 \\
\hline & ${ }^{*}$ Consejo de Apelaciones & Título III art. 43-46 \\
\hline & ${ }^{*}$ Facultades: & \\
\hline & -Asamblea de Facultad & Título III art. 52-57 \\
\hline
\end{tabular}




\section{Cuadro 1 (Continuación)}

\begin{tabular}{|c|c|c|}
\hline $\begin{array}{l}\text { Elementos } \\
\text { Constitutivos } \\
\text { de un Modelo }\end{array}$ & Concepción Contenida en la Ley & $\begin{array}{l}\text { Títulos, Capítulos } \\
\text { y Artículos que los } \\
\text { contienen }\end{array}$ \\
\hline \multirow{5}{*}{ Organización } & -Consejo de Facultad & Título III art. 58-63 \\
\hline & -Decanos & Título III art. 64-67 \\
\hline & -Escuelas & Título III art. 68-76 \\
\hline & -Consejos de Escuelas & Título III art. 69-71 \\
\hline & -Institutos & Título III art. 77-82 \\
\hline \multirow[t]{2}{*}{$\begin{array}{l}\text { Sistema de } \\
\text { gobierno }\end{array}$} & *Democrático, representativo y participativo. & $\begin{array}{l}\text { Título I art. 30-35 } \\
\text { Título III art. } \\
167-172\end{array}$ \\
\hline & Colegiada, ejecutiva y jerárquica: & $\begin{array}{l}\text { Art. } 20,26,28,62 \\
67,68,71 \text { y } 73\end{array}$ \\
\hline \multirow[t]{5}{*}{ Gerencia } & -Consejo Nacional de Universidades & \\
\hline & -Consejo Universitario & \\
\hline & -Autoridades Rectorales, Decanos, Directores, etc. & \\
\hline & Previo y Posterior: & Art. 20 y 26 \\
\hline & -Consejo Nacional de Universidades & \\
\hline \multirow[t]{3}{*}{ Control } & -Consejo Universitario & \\
\hline & -Contraloría Interna Universitaria & \\
\hline & -Contraloría General de la República & Ley de Contraloría \\
\hline Evaluación & $\begin{array}{l}\text { De las Universidades, del proceso, del curriculum, de los } \\
\text { profesores, de los alumnos, del personal administrativo y } \\
\text { obrero. }\end{array}$ & $\begin{array}{l}\text { Art. } 20,26,36,67 \\
73,149-161\end{array}$ \\
\hline Ajustes & $\begin{array}{l}\text { En las Universidades, en el proceso, en las curricula, en las } \\
\text { estructuras académicas, etc. Sólo se prohíbe la alteración } \\
\text { del régimen democrático de elección de los órganos } \\
\text { directivos. }\end{array}$ & Art. 20,26 y 187 \\
\hline
\end{tabular}

Fuente: elaboración propia.

Será necesario determinar el grado de cohesión alcanzado en cada institución y diseñar las estrategias correspondientes para que todos y cada uno de los integrantes de esa comunidad (profesores y estudiantes) internalicen y se identi- fiquen con la noble misión colectiva de buscar la verdad y afianzar los valores trascendentales del hombre.

La expresión "buscar la verdad", como dice Nicol (1965) es mas bien una manifestación de la vocación científica 
que deben tener los miembros integrantes de la comunidad universitaria por encima de cualquier otro interés.

También podemos relacionar la vocación de buscar la verdad, que el legislador venezolano aspira a desarrollar en la comunidad de intereses espirituales que la definen y conforman, con la dinámica productiva del conocimiento a que se refiere Flórez, y que ya se comentó.

La libertad entendida como posibilidad de pensar, expresar y actuar sin límites, sólo le es posible al individuo aislado, ya que nuestra naturaleza biológica nos impone los primeros límites y nos obliga a vivir en grupos para poder reproducirnos y sobrevivir. Se parte entonces de que vivir en grupos es una necesidad y en consecuencia la libertad individual y colectiva está limitada por la libertad de los otros individuos con los cuales se convive.

La noción de autonomía humana es compleja porque depende de condiciones culturales y sociales. Para ser nosotros mismos, nos hace falta aprender un lenguaje, una cultura, un saber, y hace falta que esa misma cultura sea suficientemente variada como para que podamos hacer, nosotros mismos, la elección dentro del surtido de ideas existentes y reflexionar de manera autónoma. Esa autonomía se nutre, por tanto de dependencia; dependemos de una educación, de un lenguaje, de una cultura, de una sociedad, dependemos, por cierto, de un cerebro, él mismo producto de un programa genético, y dependemos también de nuestros genes (Morin, 1997: 97-98).

Respecto a la libertad, las universidades disponen de autonomía organizativa, académica, administrativa y económi- ca que las habilita para investigar libremente cualquier área del conocimiento o tema y es indispensable para poder estar permanentemente creando y desarrollando nuevos conocimientos, pero como es lógico no son instituciones aisladas, sino que forman parte de un sistema mayor y más complejo definido en nuestra constitución (tanto la anterior como la vigente) y en consecuencia esa parte debe estar supeditada a el todo que es el Estado y la nación. Se justifica entonces que las universidades estén subordinadas y coordinadas por el Estado y que todas sus actividades estén al servicio de la nación.

La subordinación y coordinación de las universidades por el estado, así como su misión están claramente establecidas en la respectiva ley y no hay lugar a dudas de que la intención del legislador fue la de asignarle la misión de asimilar, crear, desarrollar, difundir y aplicar el conocimiento y la educación al servicio del desarrollo y el progreso de la nación. No al servicio del sistema, ni del gobierno, ni de determinada ideología, ni del mercado, ni de las empresas privadas nacionales, ni mucho menos las trasnacionales.

El problema de fondo que está involucrado es si la asimilación, creación, desarrollo y acumulación del conocimiento científico, es decir, la ciencia, nos libera, nos desarrolla o nos esclaviza y destruye.

En este sentido muy bien lo establece la vigente Constitución de la República Bolivariana de Venezuela, en su artículo 3, que la educación, a través de la cual se desarrolla la ciencia, debe ser considerada uno de los instrumentos para el desarrollo de los pueblos. 
Como instrumento que es, igual que la ciencia, puede ser usado para bien o para mal. De allí la importancia de establecer, con la ayuda de los nuevos aportes de la ética, los nuevos valores y principios en que debe basarse el modelo de desarrollo y el correspondiente modelo de Universidad, educación y pedagogía, que estamos obligados a diseñar y a poner en práctica, en función del proyecto de país que define la citada Constitución Nacional (Asamblea Nacional Constituyente, 1999).

La respuesta a este interrogante implica analizar y definir el conocimiento científico, la ciencia, la realidad, la sociedad, la nación, el Estado, el poder, el hombre, el desarrollo, así como también sus interrelaciones y la escala de valores que determina el uso que se le debe dar a la ciencia y a la educación.

\section{Resultados del análisis}

En la oportunidad en que las respectivas autoridades gerenciales universitarias decidan diseñar un programa de transformación, deben convocar a sus mejores talentos y a todos los miembros de sus respectivas comunidades para replantearse las viejas preguntas: ¿qué es la realidad?, ¿qué es el desarrollo?, ¿qué es el hombre?, ¿qué es la ciencia?, ¿cuál es el papel de la ciencia? (Méndez, 2003).

La concepción del conocimiento como producto parcelado en disciplinas, se refuerza en el artículo 47 de la mencionada ley de universidades, que establece: "Por su especial naturaleza a cada Facultad corresponde enseñar e investigar una rama particular de la ciencia o de la cultura, pero todas se integran en la unidad de la Universidad y deben cumplir los supremos fines de ésta".

También en el artículo 132 referido al Consejo de Desarrollo Científico y Humanístico se establece: ... "que tendrá por finalidad estimular y coordinar la investigación en el campo científico y en el dominio de los estudios humanísticos y sociales".

En ambos casos hay implícita una concepción disciplinar del conocimiento e incluso una valoración científica a un campo del conocimiento y a los demás los denomina estudios humanístico y sociales. Parece que los primeros son científicos y los otros no.

La actual tendencia teórica respecto al conocimiento es la de considerar la realidad conformada por una multiplicidad de elementos interrelacionados de manera compleja, directa, indirecta, concomitante, azarosa, complementaria, antagónica, y en consecuencia, no se puede estudiar de manera parcelada, aislada, lineal sino con un enfoque global, transdisciplinar.

Respecto a la educación es necesario incorporar las tendencias actuales que consideran a la educación como instrumento para el desarrollo personal y colectivo al servicio de la nación (no del mercado, ni de ideologías) y en consecuencia, debe ser considerada un servicio público que el estado está obligado a prestar de manera permanente, para toda la vida, y los ciudadanos tienen derecho a recibirla.

En el artículo 4 de la Ley de Universidades se establece "la enseñanza universitaria se inspirará en un definitivo espíritu democrático, de justicia social y de 
solidaridad humana, y estará abierta a todas las corrientes del pensamiento universal, las cuales se expondrán y analizarán de manera rigurosamente científica".

Se desprende de esa lectura que hay valores definidos y el sistema es abierto. Sin embargo hay que incorporar las más recientes teorías sobre la educación ya que enseñar implica sólo mostrar, y en la actualidad se considera a la educación como un proceso de interacción mucho más complejo cuyos múltiples elementos y sus interrelaciones debe ser tomados en cuenta al proponer los cambios necesarios en el modelo universitario.

El hecho de que se establezca que: estará abierta a todas las corrientes del pensamiento universal, facilita hacer reformas curriculares que incorporen los nuevos conceptos sobre el conocimiento, la investigación, la educación y la pedagogía.

Las nuevas concepciones exigen que los docentes se transformen de expositores del conocimiento en conductores y facilitadores del aprendizaje; y los estudiantes, de espectadores del proceso de enseñanza, en integrantes participativos y críticos en la construcción de su propio conocimiento. El sistema educativo debe asumir también el análisis permanente de los resultados y del contexto para hacer ajustes y diseñar los nuevos planes y estrategias que sean necesarias.

Respecto a la concepción pedagógica, el ordinal $5^{\circ}$ del artículo 62 que establece las atribuciones del Consejo de la Facultad, entre otras, señala: "Considerar los planes de enseñanza elaborados por las Escuelas respectiva, y elevarlos, para su aprobación final, al Consejo Universitario".
En el ordinal $6^{\circ}$ del mismo artículo se establece al mismo organismo la atribución de aprobar los programas de estudio elaborados por las Escuelas.

El término enseñanza implica que se concibe a la pedagogía como el arte de enseñar, como un proceso mediante el cual es el maestro el que enseña el conocimiento a sus alumnos, y éstos lo memorizan.

Cada Facultad, que le corresponde enseñar e investigar una rama particular de la ciencia, tiene la atribución de aprobar y elevar al Consejo Universitario, los planes de enseñanza que elaboran las escuelas, que a su vez les corresponde una especialización dentro de la rama particular de la ciencia y es la que elabora los respectivos programas de estudios. Luce excesiva la parcelación del conocimiento.

Las respuestas a los llamados interrogantes fundamentales que se han mencionado, quedan en manos de cada una de las Escuelas que conforman las Facultades. Esto constituye una fuente de poder $y$ una dificultad para establecer un modelo pedagógico común cuya misión sea la formación integral del ciudadano.

Aunque el contexto, la familia, la sociedad, el ambiente, la ciencia, la cultura, la escuela, el docente, tienen una muy importante influencia en la formación humana, y han sido objeto de análisis por las diferentes teorias pedagógicas, se consideran medios que deben ser tomados en cuenta; pero, si los individuos no asumen una actitud positiva y realizan las operaciones cerebrales y/o sensoriales y/o musculares necesarias según el caso, no se podrán lograr resultados satisfactorios en su proceso de formación. 
Los aportes de las diferentes teorías no se deben considerar excluyentes sino como complementarios. Las circunstancias de tiempo, lugar, cultura y, de manera especial, las condiciones y características de los educandos, se deben tomar en cuenta para diseñar y aplicar los planes pedagógicos que se consideren más apropiados para alcanzar de la manera más eficaz y eficiente los objetivos que previamente la sociedad a través del sistema educativo haya definido.

Todo el proceso de diseño y aplicación debe estar de manera sistemática en permanente evaluación para que se puedan hacer los ajustes necesarios e incorporar los nuevos aportes, no sólo de la pedagogía, sino del conocimiento en general.

En cuanto al modelo organizativo y de dirección la mencionada ley ubica a las universidades: como parte integral del sistema educativo, especialmente del área de estudios superiores (art. 5); coordinadas por el Consejo Nacional de Universidades (art. 18) y aunque gozan de autonomía organizativa (ordinal 1 art. 9) la misma ley les establece una organización por Facultades, Escuelas, Institutos; así como también organismos de dirección y cogobierno: Consejo Universitario, Consejo de Facultad, etc. (art. 47 y sgtes.).

Ese modelo organizativo parte de una clasificación del conocimiento en disciplinas o campos, que en la actualidad se considera una seria limitación para su desarrollo y han originado una excesiva burocracia que hace lentos los procesos de toma de decisiones, de ejecución, control y evaluación.

La tendencia actual es a flexibilizar esas clasificaciones, a propiciar la inves- tigación interdisciplinaria y transdisciplinaria y a ampliar los límites de aplicación de los métodos de investigación que servían de base a esas clasificaciones.

Respecto al sistema de gobierno, en el modelo universitario se establece que es democrático, representativo y participativo; y la gerencia, colegiada, ejecutiva y jerárquica.

La actual tendencia es a concebir la gerencia bajo el enfoque de la planificación sistemática, estratégica y participativa ejerciendo el control mediante el diálogo, la persuasión, la negociación, la concienciación del personal y su identificación con la misión de la institución y la rendición de cuentas.

Uno de los principales problemas que han enfrentado quienes gerencian procesos productivos a lo largo de la historia de la humanidad, es lograr la coordinación, eficacia, calidad y eficiencia del trabajo humano colectivo. El éxito de cualquier organización depende en gran medida de que sus gerentes logren que los trabajadores hagan las cosas bien, rápido y con el menor esfuerzo y desperdicio posible. Esto exige mecanismos de control y evaluación eficaces y eficientes que además de posibilitar la consecución de los objetivos de la organización, facilite el ejercicio del poder de los dirigentes sobre los dirigidos.

Parafraseando a (Gamboa y Suárez, 1997) el término control sintetiza diferentes medios utilizados por quienes ejercen el dominio sobre otros sujetos, para asegurar a lo largo de un proceso, el logro de los objetivos o metas previstos. El control se clasifica en ideológico y represivo o coercitivo. El represivo es aquel que utiliza la fuerza, la amenaza o cualquier me- 
dio coercitivo para evitar las alteraciones a la norma de comportamiento establecida y para represar manifestaciones de descontento o rebeldía por desacuerdo con la norma. Se utiliza directa o indirectamente diversos tipos y grados de violencia contra los sujetos controlados: violencia física, presión y diversos tipos de sanciones o formas más sutiles, como la amenaza. Una forma de control coercitivo es el control técnico.

El control ideológico es más sutil, es aquel que logra ciertos comportamientos de los individuos inculcando determinadas ideas por medio de la persuasión, la inducción, la manipulación o la concesión de algunos beneficios materiales que legitimen a quienes detentan el poder. Los fundamentos del control ideológico se encuentran en los sistemas religiosos, de parentescos y jerárquico ceremonial, que legitiman las relaciones de autoridad; se reafirman en el sistema escolar que estableces mecanismos rigurosos de selección-eliminación y de jerarquización con base en el saber (Gamboa y Suárez, 1997).

Dado el hecho de que existe en algunos seres humanos resistencia al cambio, tendencia a ahorrar esfuerzo y escaso estímulo a la superación; y como el progreso y desarrollo sólo es posible con un cambio de actitud favorable hacia el esfuerzo disciplinado y perseverante, se justifica entonces, utilizar las forma más humana de ejercer el poder: la educación, para estimular y promover el progreso y el desarrollo de la nación.

El uso que el Estado haga del poder, del conocimiento y de todos los demás recursos, debe estar, al igual que toda actividad humana, limitados por unos valores, por unos principios, que la misma nación defina al establecer mediante la Constitución Nacional y demás leyes, el proyecto de desarrollo que aspira a alcanzar.

Alcanzar todos o algunos de los fines de la vida involucra entonces una escala de valores, sino comunes, por lo menos aceptados por la mayoría de los integrantes de una nación, para que sea posible definir un proyecto de desarrollo nacional. Aún cuando tampoco hay consenso sobre un concepto de desarrollo, a los fines de este análisis y para mantener abierta la posibilidad de que se incorporen los nuevos aportes teóricos que puedan surgir, se propone la siguiente concepción: "Proceso mediante el cual el hombre, socialmente considerado, dirige su constante esfuerzo hacia un conjunto de condiciones ideales (humanas y ambientales) que definen su bienestar y le permiten la permanente superación para sí y sus semejantes" (Romero, 1988: 18).

Para alcanzar el desarrollo de la nación, si bien es cierto que el conocimiento científico, la educación y la técnica son instrumentos indispensables, también son necesarios los recursos naturales, el trabajo, el capital, la organización social, los servicios públicos, las leyes, las vías, redes y medios de comunicación $y$ en especial el estado con su función fundamental de ser el coordinador de las actividades del grupo humano que conforma la nación. Por razones de funcionalidad, sólo puede haber un único ente que coordine las actividades de una nación.

La plena libertad para asimilar, crear, desarrollar, difundir y aplicar el conocimiento y la educación debe estar al servicio del progreso y el desarrollo de la 
nación y debe excluirse la posibilidad que se le dé otro uso.

Respecto a la concepción del hombre, el artículo 1 de la mencionada ley de universidades define a los intereses que reúne a profesores y estudiantes en la tarea de buscar la verdad como espirituales, lo cual implica que existen intereses espirituales y materiales y estos no pueden existir sin el sujeto que posea esos intereses, y para tener intereses espirituales hay que tener materia y espíritu. EI modelo teórico universitario vigente contiene entonces, una concepción espiritualista del hombre, es decir, considera al hombre como un ser dotado de materia y espiritu.

Al respecto Morin (1997) concibe al hombre como un ser biológico, cultural, y que vive en un universo de lenguaje, de ideas y de conciencia. "Vamos entonces a estudiar al hombre biológico en el departamento de biología, como un ser anatómico, fisiológico, etc., y vamos a estudiar al hombre cultural en los departamentos de ciencias humanas y sociales. Vamos a estudiar al cerebro como órgano biológico y vamos a estudiar al espíritu, the mind, como función o realidad psicológica. Olvidamos que uno no existe sin el otro; más aún, que uno es, al mismo tiempo, el otro, si bien son tratados con términos y conceptos diferentes" (Morin, 1997: 89).

Morin, en su libro Los siete saberes necesarios a la educación del futuro, sobre la naturaleza del hombre, dice: "El ser humano es a la vez físico, biológi$\mathrm{co}$, síquico, cultural, social, histórico. Es esta unidad compleja de la naturaleza humana la que está completamente desintegrada en al educación a través de las disciplinas y que imposibilitan aprender lo que significa ser humano" (Morin, 2000: 19).

Aunque hasta hoy no se ha podido demostrar de manera objetiva, científica, la existencia del espíritu, tampoco se ha podido demostrar su inexistencia. Pero como hay más fundados indicios y más consenso a lo largo de toda la historia conocida del hombre; de su existencia, es más prudente continuar concibiendo al hombre como un ser dotado de cuerpo y espíritu. El modelo curricular que se proponga debe estar abierto a ésta concepción.

La Gerencia universitaria y la de cada Facultad, Escuela, por mandato de la ley debe ser elegido por votación (régimen democrático) y esto ha originado grupos de electores que pueden tener intereses y programas de gobierno diferentes a los de otros grupos y generar resistencia a los cambios.

Para superar estas resistencias, será necesario diseñar estrategias muy bien elaboradas y negociadas con los actores para que le den viabilidad política a los proyectos de transformación que se propongan.

A manera de referencia podemos citar el caso de la Universidad del Zulia que en diferentes oportunidades ha aprobado programas de reforma, entre los cuales destaca el de creación la Facultad Experimental de Ciencias en 1973. Algunas de las reformas contenidas en el programa, han permanecido hasta la fecha, sin embargo, otras, relacionadas con el currículo, de manera sucesiva se han venido derogando y sustituyendo por otras. La más reciente modificación del currículo fue aprobada por su Consejo Universi- 
tario mediante Resolución 535 de fecha 15-11-2006.

Aunque las razones por las cuales no se ha logrado un proceso de transformación profunda en la Universidad del Zulia debe ser objeto de otro proyecto de investigación, sin embargo, en una primera aproximación pudiera partirse de la hipótesis de que afectaban a grupos que detentan poder y han logrado revertir parte de las transformaciones propuestas.

Para que pueda tener posibilidades de aceptación por parte de la comunidad universitaria y de sus respectivas autoridades, se debe utilizar tanto para el diagnóstico como para las propuestas, las técnicas de planificación participativa, abierta a todos sus integrantes, a fin de conocer sus expectativas y generar ideas, propuestas y programas de cambio o transformación con proyectos específicos en los cuáles se establezca con la mayor precisión posible: ¿qué hacer?, ¿cómo?, ¿para qué?, ¿con qué?, ¿quién?, ¿cuándo?, así como también los correspondientes planes de negociación, entrenamiento y motivación para el personal que tendrá a su cargo la aprobación, puesta en marcha, evaluación, control y ajustes del proceso de cambio o transformación.

\section{Conclusiones}

El modelo pedagógico universitario contenido en la vigente ley de universidades está fundamentado en una concepción del conocimiento como producto, como saberes, que se pueden clasificar y dividir en parcelas (disciplinas).

Está desactualizado, se ha generado excesiva especialización, frondosidad curricular y administrativa, dispersión de recursos, aislacionismo, redes de poder. Se debe asumir y aplicar la actual concepción compleja del conocimiento y la transdisciplinaridad.

La concepción pedagógica, contenida en el modelo universitario, se basa en el conocimiento como producto que se puede enseñar a los alumnos y que estos los guarden en su memoria. Hace énfasis en el conocimiento y en el maestro y subestima el papel del entorno y del alumno en el proceso de su propia formación. La actual tendencia es a asumir y aplicar la concepción de Formación humana integral y el constructivismo.

Es necesario, también, asumir y aplicar la concepción de la educación establecidas en la Constitución Nacional, que la consideran instrumento para el desarrollo personal y colectivo al servicio de la nación (no del mercado, ni de ideologías) y en consecuencia, debe ser considerada un servicio público que el estado está obligado a prestar de manera permanente, para toda la vida, y los ciudadanos tienen derecho a recibirla.

El modelo universitario es abierto y tiene previsto los mecanismos y procedimientos para que la gerencia de las mismas Universidades Públicas Autónomas, en uso de su autonomía, hagan las transformaciones que sean necesarias para estar incorporando los avances de la ciencia, la tecnología y en general de la cultura y su aplicación a la solución de los problemas relacionados con el desarrollo del individuo y de la nación.

En los respectivos programas de transformación se debe establecer un adecuado sistema de control en el que predomine el control ideológico y de re- 
sultados, sobre el represivo, las técnicas de planificación participativa, las estrategias de negociación tanto al interior de las instituciones como en sus relaciones con el entorno.

\section{Referencias bibliográficas}

Asamblea Nacional Constituyente de la República Bolivariana de Venezuela (1999) Constitución de la República Bolivariana de Venezuela.

Congreso de la República de Venezuela (1970). Ley de Universidades.

Consejo Universitario de la Universidad del Zulia (2006). Resolución 535 del 15-112006.

Drucker, Peter (1999). Los desafíos de la gerencia para el siglo XXI. Colombia. Grupo Editorial Norma.

Flórez, Rafael (2005). Pedagogía del Conocimiento. Colombia. McGraw-Hill Interamericana, S.A.

Frases de Platón (www.google.co.ve) consulta 21-06-2008.

Gamboa, Teresa y Suárez, Cira (1997). Control y evaluación: funciones claves del Poder económico. Revista Venezolana de Ciencias Sociales. Vol.1 No 1. pp. 53-75.

Ibarra, Eduardo (1996). Educación superior y teoría de la organización: posibilida- des y problemas de una relación impostergable. Revista Universidad Futura. Vol. 7 No $20-21$.

Lander, Edgardo (2000). ¿Conocimiento para qué? ¿Conocimiento para quién? Reflexiones sobre la geopolítica de los saberes hegemónicos. FACES. Universidad Central de Venezuela. Vol. $6 \mathrm{~N}^{\circ} 2$.

Méndez, Evaristo (2003). Cómo no naufragar en la era de la información. Maracaibo, Venezuela. Ediluz.

Morin, Edgar (1997). Introducción al pensamiento complejo. Barcelona, España. Editorial Gedisa, S.A.

Morin, Edgar (2000). Los siete saberes necesarios a la educación del futuro. Caracas, Venezuela. Ediciones FACES-UCV.

Navarro, Rubén (2008). El concepto de enseñanza aprendizaje. (www.redcientifica.com) consulta 25-02-2008.

Nicol, Eduardo (1965). Los principios de la ciencia. México. Fondo de cultura Económica.

Romero, Néstor (1988). Reflexiones para una nueva concepción del desarrollo y del Sudesarrollo. Maracaibo, Venezuela. Ediluz.

Vicaría Episcopal de Educación del Arzobispado de Buenos Aires. (2008) Concepto de Educación. (www.educare.org.ar) consulta 25-02-2008. 